\title{
La salud en el Perú en tiempos del coronavirus: 60 días después, ¿sin reflexión?
}

\section{Health in Peru in coronavirus times: 60 days later, without reflection?}

\author{
Jesus Lorenzo Chirinos-Cáceres '
}

Este periodo que ha pasado nos permite inferir, sin mucha reflexión dadas las noticias, que estamos entre el COVID-19 y la corrupción, situación lamentable, ya que en la posición media se encuentra el pueblo peruano $\mathrm{y}$, como se dice "tras cuernos palos". ${ }^{1,2,3}$ La situación del mercado de insumos de salud en el exterior es calamitosa con las pugnas de los países que ostentan ingresos altos con los que son intermedios, y no contemos a los bajos, ya que los de mayor riqueza hasta "piratean" a los de menor riqueza, caso de confiscaciones de mascarillas, ventiladores, equipos para pruebas moleculares y las propias pruebas.

Revisando la información hasta la actualidad, podemos señalar, también sin mucha reflexión, que este coronavirus ha desnudado todas las falencias, tanto humanas, comunitarias y de organizaciones sociales, los sistemas de salud y sociales, al solo ver las noticias sobre la ejecución de la prevención del contagio de manera individual o comunitaria o estatal, llámese lavado de manos o uso de alcohol, no tocarse la cara, mascarillas, guantes o no, distanciamiento físico, aislamiento, cuarentena y cierre de fronteras, que no se cumplen al $100 \%$ a pesar de los múltiples llamados avisos o spots publicitarios, entre otros; y, la colaboración a esta ruptura por parte del sector público al no haber previsto con anticipacióon la necesidad de estos materiales y de la educación sanitaria necesaria, no ser sancionadores del incumplimiento y, también, al establecer los bonos que eran muy necesarios pero sin la debida previsión de la muy probable ruptura de estas medidas de prevención al salir a los bancos, supermercados, mercados y no haber previsto que estos podían ser focos de contagio. Como ejemplo podemos señalar algo incongruente y que

Médico internista. Decano de la Facultad de Salud Pública, Universidad Peruana Cayetano Heredia.
Chirinos-Cáceres, J. La salud en el Perú en tiempos del coronavirus: 60 días después, ¿sin reflexión?. Rev Soc Peru Med Interna. 2019;33(2): 56-57. https://doi.org// 0.36393/spmi.v33i2.520

debe llevar a la reflexión, es que el poblador peruano le tiene mas miedo al hambre que a la infección por coronavirus, pudiendo decir que el hambre puede ocasionar problemas a mediano plazo, pero el coronavirus puede tornarse severo en promedio en once días y matar, con una necesidad urgente de oxígeno, tanto que necesitas una cama UCI, los cuales escasean en estos momentos por la saturación de los hospitales ante la rapidez de contagio, agresividad y progresión de la enfermedad en personas de mayor vulnerabilidad. ${ }^{4,5}$

Luego de pasados sesenta días podemos decir, de acuerdo al preámbulo anterior, que era previsible, de acuerdo a nuestro criterio, sentido común y sexto sentido, que las cifras de contagiados, hospitalizados, usuarios de una cama UCI y de respiradores mecánicos y de fallecidos iba a crecer exponencialmente, lo que ya se veía hace ds meses y que la economía iba a caer también dados los aislamientos y la cuarentena para poder dar los"martillazos a las curvas" y que el comportamiento individual y comunitario así como de los sectores públicos respectivos se dedicó a "desmartillar.

A la fecha se tiene un acumulado de 4307287 casos confirmados en el mundo (1 458243 en EE.UU., España con 274 367, Rusia, Reino Unido, Italia, Brasil, Francia, Alemania, Turquía e Irán con cifras aproximadas de 263 000 a 117 000). Mientras, el número de fallecidos es de 158819 en Europa (Reino Unido con 33 614, siguiendo Italia, España y Francia con cifras aproximadas que van algo más de 31000 a 27 000); y, 117079 en América (en primer lugar EE.UU. con 86 942, en el sexto Brasil con 13 999). ${ }^{6}$ Por otro lado, en el Perú tenemos 84495 casos confirmados (pasamos a China con 82933 casos y estamos segundos en Latinoamérica, luego de Brasil, con posiciones contrapuestas de sus respectivos presidentes), con 7085 hospitalizados, 851 en UCI y 2392 fallecidos, de los cuales $72 \%$ son varones y mayores de 55 años la mayoría. ${ }^{7}$ 
Aquí debo detenerme para señalar que cuando se ha visto este rápido crecimiento de la enfermedad en pocos meses o cuando la salud de una autoridad se ha afectado en países de ingresos altos cuyos sistemas de salud ocupaban puestos de primera línea en el mundo, y que mostraban desenfado o indiferencia o soberbia, cambiaron radicalmente de posición con respecto a las medidas preventivas que señalamos párrafos arriba. Inmediatamente solicitaron a la población cambios de comportamiento, algo tardío, pero aún persisten algunos que insisten en que no hay problema alguno con este virus.

Con las medidas tomadas ganamos el tiempo necesario para permitir cierto control de la enfermedad, sobre todo en el uso de camas UCI y de ventiladores; sin embargo, se olvidó elementos indispensables como el oxígeno, los equipos de protección personal y los medicamentos, que se han ido probando con resultados promisorios pero no con evidencia científica, y sin tener aún una vacuna o anticuerpos para aplicar a la población. Además, es muy lamentable que haya ocurridoel fallecimiento de personal de salud que es la primera línea que enfrenta a esta enfermedad, teniendo a la fecha 20 médicos fallecidos, así como enfermeros y técnicos.

¿Qué nos espera? A modo de reflexión debemos mirar hacia adelante con una visión compartida de sobrepasar esta crisis y hacer un plan de sostenibilidad y de recuperación en todo sentido. De sostenibilidad del sistema de salud, buscando por lo menos una integración de lo fragmentado o disminuir su precariedad; y, de recuperación de la vida cotidiana conviviendo con el coronavirus de manera inteligente, utilizando las medidas de prevención al levantameinto de la cuarentena y ser conscientes de aislarnos por nosotros mismos en el momento de presentar síntomas. Debemos insistir en la educación sanitaria e higiene, siguiendo los pasos y experiencias de los que ya están volviendo a una "normalidad COVID" porque tendremos oleadas de aparición de nuevos casos; y, así aparezca un medicamento o vacuna o anticuerpos a aplicar, debemos mantener las medidas de prevención por las mutaciones probables del virus que ocurran al futuro.

Nuevamente, nuestro agradecimiento más profundo a nuestros profesionales de salud y personal de salud en general que a pesar de las condiciones continúa enfrentando la epidemia con altura y esperanza. Seguiremos esperando y brindaremos nuestro granito de arena para que nuestro sistema de salud entre en reestructuración verdaderamente y que los profesionales y personal de salud encuentren el bienestar y las condiciones de trabajo adecuadas en el desarrollo de su profesión y trabajo. Algunos haremos trabajo remoto, otros presenciales, pero siempre bajo las medidas preventivas y no las impositivas que con o sin razón van contra la ética y los derechos del ser humano. También seguiremos buscando que la corrupción sea revertida y sancionada en todo momento y que se aplique todo el rigor de la ley.

\section{REFERENCIAS BIBLIOGRÁFICAS}

1. García PJ. Lecture: Corruption in global health: the open secret. The Lancet/The Academic Medical Sciences. Published Online November 27, 2019 https://doi.org/10.1016/ S0140-6736(19)325279 www.thelancet.com http://dx.doi.org/10.1016/S0140-6736(19) 32527-9

2. Chirinos-Cáceres JL. La corrupción en el sector salud: ¿A quién afecta? Rev Soc Peru Med Interna. 2019;32(4): 125-126. https://doi. org/10.36393/spmi.v32i4.489

3. Chirinos-Cáceres JL. COVID-19: La salud en el Perú en tiempos del coronavirus: A reflexionar. Rev Soc Peru Med Interna. 2019;33(1):10-11. https://doi.org/10.36393/spmi.v33i1.504

4. Berlin DA, Gulick RM, Martinez FJ. Severe Covid-19. May 15, 2020, at NEJM.org. URL disponible en: https://www.nejm.org/doi/ pdf/10.1056/NEJMcp2009575?articleTools=true

5. Zhao X, Zhang B, Li P, Ma C, Gu J, Hou P, et al. Incidence, clinical characteristics and prognostic factor of patients with CVID-19: a systematic review and meta-analysis. Preprint. MedRxiv. URL disponibleen:https://www.medrxiv.org/content/10.1101/2020.03.17. 20037572v1

6. Statista. Salud e industria farmacéutica. Estado de salud. Número de personas fallecidas a consecuencia del coronavirus a nivel mundial a fecha de 15 de mayo de 2020, por continente. URL disponible en: https://es.statista.com/estadisticas/1107719/covid19numero-de-muertes-a-nivel-mundial-por-region/

7. Sala situacional COVID-19, Perú. Actualización hasta las 0.00 horas del 15 de mayo 2020. https://covid19.minsa.gob.pe/sala_situacional. asp

Lima, 18 de mayo del 2020.

\section{CORRESPONDENCIA}

jesus.chirinos@upch.pe 